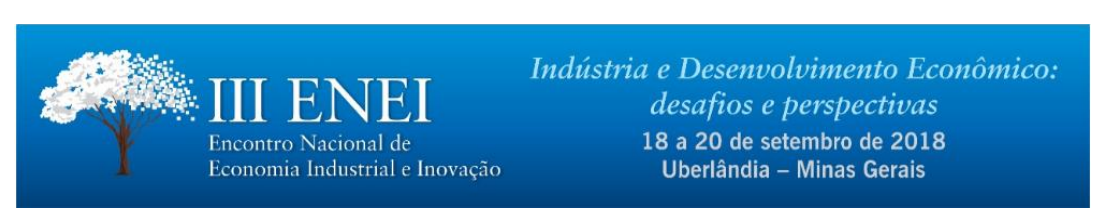

\title{
UMA VISÃO DE POLÍTICA INDUSTRIAL PARA O BRASIL: RESULTADOS A PARTIR DE UMA PROPOSTA DE MATRIZ TECNOLÓGICA*
}

\author{
Thiago Miguez, Gabriel Daudt, Bruno Plattek, Luiz Daniel Willcox e Sergio Schmitt•
}

\section{AREA ENEI: 6.2. Políticas de Ciência, Tecnologia e Inovação}

\begin{abstract}
RESUMO
Há uma conhecida literatura que aborda que diversos países, notadamente os países centrais, passaram ou vem passando por uma perda de seus tecidos industriais nas últimas décadas. Por outro lado, é necessário reconhecer que recentemente há um movimento de vários países no sentido de reforçar suas indústrias nacionais (reshoring), como a Indústria 4.0 na Alemanha e a Manufatura Avançada nos EUA. No Brasil não está sendo diferente, além da falta de competitividade da indústria nacional, e a consequente queda de participação desta no PIB, há iniciativas em andamento que buscam recuperar o setor e/ou desenvolver novos segmentos. Nesse sentido, o presente trabalho contribui com um mapeamento sobre as principais tecnologias, e suas bases de conhecimento, com o potencial de absorção setorial para o Brasil e os entraves do ambiente institucional que o cerca. Desse modo, é possível conjugar tanto a política tecnológica como a política industrial em uma mesma ferramenta analítica. Tal mapeamento foi obtido por meio da aplicação de dois formulários junto a alguns especialistas e permitiu identificar, por exemplo, as bases de conhecimento mais transversais - "Manufatura Padrão e Avançada", "Eletrônica e Ótica Avançadas" e "Biotecnologia" - e os setores mais diversificados nas suas demandas tecnológicas "Petróleo e Gás", "Complexo da Saúde" e "Aeroespacial e Defesa".
\end{abstract}

Palavras-Chave: Política Industrial; Política Tecnológica; Políticas Públicas; Inovação; Matriz Tecnológica;

\begin{abstract}
There is a well-known literature reporting that several countries, notably the developed ones, have been passing through a loss of their respective manufacturing production in the last decades. On the other hand, it must be recognized also that there is a recent movement in several countries to strengthen their national manufacturing (reshoring), such as Industry 4.0 in Germany and the Advanced Manufacturing Initiative in the USA. In Brazil it is not different. Besides the lack of competitiveness of the local manufacturing, and the consequent fall of its GDP share, there are ongoing initiatives that seek to recover the sector and develop new segments. This paper tries to contribute to these topics introducing an analysis for Brazilian main opportunities on technological demands, and their knowledge bases, with the potential sectoral absorption and and the obstacles on the institutional environment. By doing so, it is possible to combine both technological and industrial policy in the same analytical tool. Two forms were applied to some specialists and the results allowed the identification, for example, of the most transversal technologies "Standard and Advanced Manufacturing", "Advanced Electronics and Optics" and "Biotechnology" - and the industries with a more diversified technological demand - "Oil and Gas", "Health" and "Aerospace and Defense".
\end{abstract}

Keywords: Industrial Policy; Technological Policy; Public Policies; Innovation; Technological Matrix;

JEL Codes: L52, L60, L70, O12, O14, O25, O30

\footnotetext{
- As informações, opiniões e análises contidas neste documento são de única e exclusiva iniciativa dos autores e não necessariamente representam a opinião, estratégia e posicionamento do Sistema BNDES sobre os assuntos tratados.

Os autores agradecem a seus colegas de BNDES que pacientemente responderam aos formulários desenvolvidos para a elaboração deste trabalho e aos de comentários de Leandro Gomes, Vitor Pimentel, Carla Reis, William Saab e do parecerista do III ENEI, isentando-os de qualquer responsabilidade.

- Todos os autores são do Banco Nacional de Desenvolvimento Econômico e Social (BNDES).
} 


\section{INTRODUÇÃ̃O}

O presente trabalho parte de uma literatura que enfatiza que o setor industrial possui um papel relevante para o desenvolvimento econômico. Como se sabe, é possível argumentar que a importância da indústria advém de características como, por exemplo, demandar mão-de-obra qualificada, demandar serviços de alto valor agregado, ser um setor intensivo em inovação e também pela sua capacidade de mitigar restrições de Balanço de Pagamentos, aspecto este especialmente relevante em países periféricos. Há também uma conhecida literatura que aborda que diversos países vêm passando continuamente por uma perda de seus respectivos tecidos industriais. De fato, a partir da década de 1970 emerge uma grande preocupação com a perda de empregos industriais nos países avançados, sendo a Inglaterra o caso emblemático e os EUA o caso de recente notoriedade - com a eleição de Donald Trump enquanto uma manifestação de questões subjacentes, dentre outras coisas, a perda destes empregos no país.

Nesse sentido, é necessário reconhecer o movimento de vários países no sentido de reforçar suas indústrias nacionais. Para tanto, eles têm procurado recuperar algumas das atividades "perdidas" (especialmente após a ascensão da China) e também estimular o desenvolvimento e a criação de novos mercados. Esse movimento vem sendo liderado, principalmente, pelos países de industrialização madura que perderam participação industrial - como EUA, Alemanha, Inglaterra e Japão - mas também conta com iniciativas relevantes de países emergentes - como China e Índia que buscam maior protagonismo global. Chama a atenção que, além da tentativa de retomar a primazia industrial, há bastante ênfase nas chamadas tecnologias habilitadoras (key technologies).

Tradicionalmente, os estudos existentes no Brasil sobre desenvolvimento e políticas industriais partem de um ou alguns diagnósticos setoriais específicos, incluindo uma visão de futuro e a identificação de um problema específico. Ao mesmo tempo em que isso permite um aprofundamento do conhecimento setorial, possibilitando que problemas específicos sejam reconhecidos e solucionados, tal recorte por vezes dificulta que uma visão de conjunto seja implementada ${ }^{1}$. Assim, o objetivo geral do presente trabalho é apresentar um arcabouço analítico que trate de forma integrada os diversos setores industriais e as tecnologias que estão sendo desenvolvidas, agregando-as por bases de conhecimento e sistemas industriais mais promissores. Desse modo, acredita-se que seja possível oferecer melhores propostas para a promoção do desenvolvimento industrial e do adensamento produtivo.

A construção aqui apresentada toma como referência a proposta de Andreoni (2017), ainda que com adaptações próprias. Utiliza-se como premissas que: (i) a unidade de análise deve ser a indústria vista em seu conjunto, e não apenas com os seus setores de forma isolada; (ii) a política de inovação e a política industrial devem ser tratadas de forma articulada; e (iii) deve-se utilizar como base o conceito de tecnologias habilitadoras (bases de conhecimento) e desafios a serem superados. Assim, partindo de uma abordagem matricial, cotejando as bases de conhecimento e a dinâmica estrutural setorial, serão avaliadas alternativas de ações integradas de apoio ao desenvolvimento industrial.

O presente trabalho está dividido em mais cinco seções além desta introdução. A segunda seção destaca que está em curso, em diferentes países, um movimento de retomada das políticas industriais e também traz um rápido panorama da economia brasileira nos últimos anos. Apresentase alguns números para evidenciar que a indústria não conseguiu crescer no mesmo ritmo que a economia como um todo, levando a um aumento das importações e tornando urgente construir uma visão de futuro que resgate sua competitividade. Na terceira seção é apresentada uma metodologia que congrega os aspectos tecnológicos e setoriais, baseado em Andreoni (2017), que busca justamente contribuir para a construção dessa visão. Na quarta seção são apresentados os resultados da aplicação dessa metodologia a partir das informações obtidas em pesquisa dentro do Banco

\footnotetext{
${ }^{1}$ Nesse sentido, é importante lembrar que os processos produtivos ocorrem por meios de fluxos intersetoriais, ou seja, qualquer atividade econômica possui desmembramentos "para trás" (compra de insumos de outras atividades) e para frente (venda para outras atividades ou consumidores). Essas interpelações ocorrem em última instância ad infinitum, portanto, ao não enxergar a atividade industrial como um fluxo intersetorial há perdas de informações e de sinergia.
} 
Nacional de Desenvolvimento Econômico e Social (BNDES). Na quinta seção há uma análise complementar ao mapeamento exposto na Matriz Tecnológica, chamada de Ambiente Institucional, onde se pretende apontar, de forma não exaustiva, fatores estruturais que condicionam o desenvolvimento tecnológico no Brasil nos diversos setores. A última seção traz as conclusões de praxe e fornece, de maneira ilustrativa, algumas indicações de atuação a partir do ferramental construído.

\section{IMPORTÂNCIA DA INDÚSTRIA}

O processo de industrialização foi o alicerce que permitiu o desenvolvimento de diversos países, fazendo com que novos mercados surgissem, a produtividade se elevasse e a renda per capita aumentasse. É importante mencionar que esse processo ocorreu de modo diverso nas distintas economias, ou seja, não apenas as trajetórias de industrialização foram diferentes, como também os resultados não foram os mesmos. Do ponto de vista histórico, enquanto os países centrais atingiram o desenvolvimento econômico e social, outros, apesar de relativo sucesso no processo de industrialização de suas economias, adotaram um modelo de industrialização subordinada - ou “associada e dependente" na expressão dos anos $1960^{2}$.

No entanto, especialmente durante as décadas de 1980 e 1990, ganhou ampla aceitação a ideia de que a política industrial deveria cair em desuso ou, como colocado por Wade (2017), de que ela teria se tornado "tóxica". Economistas marginalistas de renome enfatizaram exaustivamente os malefícios da política industrial, inclusive considerando que a indústria não seria particularmente importante vis-à-vis os demais setores da economia. De forma muito geral, esses economistas consideram que a alocação promovida pelo mercado geraria o resultado mais eficiente, enquanto a intervenção em favor do setor industrial seria convidativa a práticas de rent seeking.

No presente trabalho, partimos de uma literatura oposta ao mainstream, ou seja, que confere à indústria um papel de destaque. Como se sabe, as chamadas "três leis de Kaldor" encapsulam a relevância do setor manufatureiro para o crescimento econômico, para o crescimento da produtividade e também do emprego ${ }^{3}$. Andreoni e Chang (2016), por exemplo, vão sustentar que esse setor é a principal fonte de ganhos de produtividade da economia. O setor se configura como um "learning centre" das economias modernas ou como um grande difusor de inovações em termos tecnológicos - aspecto central em Rosenberg (1963). Os autores também destacam o papel da manufatura como fonte de inovações organizacionais e como fonte de demanda por atividades de alta produtividade nos demais setores. Ainda, cumpre lembrar que Prebisch (1949) há tempos já alertava para a essencialidade desse setor na superação dos problemas crônicos de Balanço de Pagamentos dos países periféricos.

Desse modo, ao enxergar tais particularidades na indústria, essa outra parcela de economistas vê utilidade na promoção de políticas industriais e tecnológicas. Entretanto, certamente ela não é uma panaceia e os resultados esperados podem não ser obtidos dependendo de diversas circunstâncias. Assim, vale sublinhar que, nos termos de Wade (2015), a política industrial é apenas uma "inner wheel" cujos efeitos dependem bastante de "outer wheels" - como, por exemplo, as condições macroeconômicas (inclusive relativa à taxa de câmbio) ou as coalizões políticas subjacentes.

De fato, a experiência histórica mostra que diversos países hoje desenvolvidos se valeram - e ainda se valem - do uso de políticas específicas para transformar sua estrutura produtiva, por exemplo, Chang (2004) mostra que houve um esforço deliberado de vários países no sentido de dar proeminência aos seus setores industriais. Por sinal, os Estados Unidos (EUA) é um país

\footnotetext{
2 Pode-se dizer que esse modelo é marcado por um processo permanente e instável de catching-up tecnológico, dentre outras razões, pelas dificuldades inerentes ao alcance que políticas de inovação têm quando a base industrial de um país tem a forte presença de empresas multinacionais. Tal característica implica que as principais decisões estratégicas são tomadas fora do território e, portanto, que as políticas públicas acabam tendo seu alcance limitado.

${ }^{3}$ Para uma referência explicativa sobre as três leis de Kaldor recomenda-se Thirlwall (1983).
} 
emblemático nessa questão, sendo o maior exemplo de nação a usar intensivamente, e até hoje, políticas industriais e tecnológicas ${ }^{4}$.

Além da ampla evidência histórica, o período recente trouxe um ressurgimento mais amplo da visão de que a indústria é um setor destacado. Wade (2015) afirma que a Grande Recessão abalou a confiança generalizada na ideia de que "mercados livres" e "Estados pequenos" são soluções superiores. De fato, a crise de 2007-2008 realçou o interesse pelas políticas industriais. Porém, como destacam O'Sullivan et al. (2013), isso se dá considerando também a natureza da produção manufatureira. Em paralelo com a ascensão e industrialização da China - grande mudança estrutural dos anos 2000 -, há também uma crescente fragmentação da produção. Cada vez mais, os bens estão sendo feitos em estágios separados e, como documentado na literatura ${ }^{5}$, nas últimas décadas houve um contínuo crescimento do comércio de bens intermediários. Como resultado do processo de fragmentação da produção, ocorreram mudanças na estrutura industrial global (em termos de localização, governança, propriedade da produção, etc.), com aumento da importância de alguns países emergentes ${ }^{6}$.

Inclusive, a concorrência cada vez mais acirrada por meio da diferenciação de produtos implica que as eventuais especificidades técnicas e o tamanho dos grandes mercados periféricos, como Brasil, Índia e China, por exemplo, sejam foco de atenção de empresas multinacionais. Aliado a isso, a necessidade de contrapartidas para atuação nesses mercados, tais como cláusulas de conteúdo local, transferência tecnológica e parcerias (joint ventures) com empresas locais, criaram novos incentivos para maior cooperação. Assim, atualmente, não apenas a produção física encontrase globalizada, já é possível observar que as grandes empresas também passaram a internacionalizar (ainda timidamente) a produção de conhecimento e inovação ${ }^{7}$.

Um segundo aspecto que devemos ressaltar é que as atuais experiências de política conferem bastante ênfase às tecnologias habilitadoras - ou tecnologias relativamente "genéricas", que podem formar uma base de conhecimento ampla e robusta, a partir da qual conjuntos particulares de aplicações e outras tecnologias podem ser desenvolvidos ${ }^{8}$. O foco em diversas tecnologias habilitadoras permeia iniciativas importantes de países, como é o caso da "Advanced Manufacturing Initiative" nos EUA, da "High Tech Strategy" na Alemanha, da "Foresight" no Reino Unido, da "Nouvelle France Industrielle" na França, da "Made in China 2025" na China e da "Make in India" na Índia".

Nesse contexto, a discussão sobre desindustrialização e, em última instância, sobre a própria importância da indústria, ganhou destaque nos debates sobre economia brasileira nos últimos anos. De um lado, há uma parcela de economistas, mais associada ao mainstream econômico, que entende que essa discussão não é necessária, pois não vê no perfil de especialização produtiva algo determinante para a trajetória de crescimento de longo prazo da economia. Dos trabalhos brasileiros de cunho ortodoxo, Bacha e de Bolle (2013) reúnem algumas análises representativas. Bonelli et al. (2013), por exemplo, afirmam que o Brasil acompanha a tendência global pela qual diversos outros países estão passando. O problema estaria no modelo pró-indústria que vigorou até a década de 1980: houve uma industrialização excessiva, ou uma "doença soviética", que precisou ser enxugada posteriormente, rumo a um padrão normal. Já outro grupo de economistas entende que diferentes setores, e, portanto, diferentes padrões de especialização produtiva, são capazes de gerar impactos

\footnotetext{
${ }^{4}$ Cohen e DeLong (2016) constituem-se referência recente sobre os EUA. Baseados em pesquisa histórica, mostram como o governo estadunidense e suas políticas direcionadas tiveram profunda importância para moldar e transformar a economia.

${ }^{5}$ Ver Baldwin (2016), para uma referência recente.

${ }^{6}$ Para maiores detalhes, ver O’Sullivan et al. (2013). Acerca da nova natureza da produção, os autores exploram: a diminuição da parcela da atividade manufatureira dos países da OCDE; o aumento da concorrência das economias emergentes; a demanda crescente por uma produção "resource-efficient"; a crescente complexidade e importância das cadeias globais de valor; e o acelerado ritmo da mudança tecnológica.

${ }^{7}$ Logo, começou a ser parte da estratégia das empresas a instalação de laboratórios e centros de pesquisa internacionais, mesmo nos países periféricos, buscando atender a necessidades técnicas, regulatórias e, claro, também reduzir custos. Simultaneamente isso permite que elas acessem novos mercados e/ou mantenham uma posição competitiva nos mercados já dominados ou relevantes.

${ }^{8}$ Ver, por exemplo, Tassey (2008).

${ }^{9}$ A respeito de algumas dessas iniciativas, ver O'Sullivan et al. (2013) e Daudt e Willcox (2016).
} 
diferenciados na economia per se. ${ }^{10}$ Squeff (2012) faz parte desse segundo grupo e consegue trazer mais sobriedade ao debate, discutindo a própria existência de um processo de desindustrialização.

Os números recentes sobre o desempenho da economia brasileira e da sua indústria vêm acirrando esse debate. A trajetória da economia brasileira durante os anos 2000 foi de retomada de melhores taxas de crescimento, ocorrida em função de uma combinação de fatores externos e internos ${ }^{11}$. Enquanto nos anos 1980 e 1990 a taxa de crescimento média foi de, respectivamente, 2,9\% a.a. e 1,7\% a.a., nos anos 2000 ela foi de 4,1\% a.a., sendo que no melhor período de 20032010 ela foi de 4,5\% a.a. Já os anos 2010 são de forte desaceleração, com uma média de crescimento de $1,7 \%$ a.a. entre 2011 e 2014 e dois anos seguidos de recessão em 2015 e 2016, com taxas, respectivamente, de $-3,8 \%$ e $-3,6 \%$, culminando com uma perda acumulada de 7,3\%.

Os resultados positivos da economia nos anos 2000 levaram a um crescimento também da indústria de transformação. No entanto, esse crescimento ocorreu a uma taxa menor que a da economia como um todo, apenas $2,7 \%$ a.a. para todo período $2000-2010$ e apenas 3,1\% a.a. para o subperíodo 2003-2010. Os resultados nos anos 2010 são ainda piores, com taxas médias negativas já no período 2011-2014 de -1,4\% a.a., que se agravaram ainda mais nos anos de 2015 e 2016 onde se observaram, respectivamente, as taxas de $-10,4 \%$ e $-5,2 \%$. Se combinados todos estes resultados dos anos 2010, o valor adicionado da indústria retrocedeu acumuladamente quase um quinto de seu valor.

Simultaneamente, a demanda por importações cresceu de modo significativo no período, começando a perder força apenas a partir de 2014. No período de 2003-2014 as importações de produtos industriais cresceram 15,4\% a.a., passando de US\$40,5 bilhões para US\$196,7 bilhões. Esses resultados levaram a balança comercial de produtos industrializados a déficits crescentes e acentuados, principalmente nos produtos de maior valor agregado. Apenas a recessão dos dois últimos anos foi capaz de interromper a trajetória de crescimento das importações, que caíram 23,4\% em 2015 e 17,6\% em 2016.

Assim, é importante ressaltar que a combinação de um crescimento pouco expressivo da indústria nacional (comparativamente ao desempenho do restante da economia), com um volume crescente de produtos importados, indica que a indústria está enfrentando problemas de competitividade. Esses problemas podem tanto estar relacionados a questões macroeconômicas, em particular a instabilidade da taxa de câmbio e a sua tendência à valorização como forma de controle inflacionário, como também a questões estruturais dentro da própria indústria brasileira, valendo apontar as baixas taxas de investimento em capital fixo e também os baixos investimentos em inovação.

A discussão que se segue parte, como dito, de uma visão de que possuir setores industriais bem desenvolvidos é um fator importante para o desenvolvimento de um país. Além disso, entendese que uma indústria moderna possui como principais características a demanda por mão-de-obra qualificada e o investimento em inovações de produtos e processos. Também é importante ressaltar que é a indústria que apresenta os maiores efeitos de encadeamento sobre outros setores. Inclusive, mais recentemente essa integração vem aumentando para fora da própria indústria com o aumento da demanda por serviços de alto valor agregado.

Dessa forma, independentemente da premissa adotada pelo Brasil para aumentar a efetividade de sua política tecnológica e industrial - construir uma base industrial nacional e/ou buscar uma cooperação mais intensa com as empresas multinacionais já instaladas - é importante que novas oportunidades de atuação sejam mapeadas. Essas oportunidades podem incluir o desenvolvimento de tecnologias que: i) avancem em características positivas já existentes, como os novos desafios postos a setores tradicionais como agricultura e petróleo (resource-based strategy); ii) busquem resgatar a competitividade de setores industriais enfrentando problemas de competitividade; ou

\footnotetext{
${ }^{10}$ Uma referência sobre este debate pode ser encontrada em Hiratuka e Sarti (2017).

${ }^{11}$ Serrano e Summa (2011) trazem um panorama das causas da retomada da economia brasileira nos anos 2000.
} 
ainda iii) desenvolvam novas áreas de conhecimento e atividades econômicas, sejam elas industriais e/ou de serviços.

Entendendo que possuir uma indústria competitiva é central para o desenvolvimento do Brasil, é importante que se crie uma "orientação de futuro" para a indústria. O ideal é que essa orientação parta de uma visão integrada dos principais desafios presentes nos diversos setores industriais, identificando as tecnologias habilitadoras e os sistemas industriais mais promissores, concatenando as políticas produtivas e tecnológicas. Esse objetivo vai ao encontro dos esforços de outros países de identificar tecnologias necessárias para o (re)desenvolvimento da indústria, viabilizando simultaneamente um processo de reshoring e de desenvolvimento de novos mercados. A seção seguinte apresenta um ferramental para tentar contribuir com tal objetivo.

\section{METODOLOGIA DO ESTUDO}

A integração entre as políticas industrial e tecnológica é uma necessidade frente ao avanço crescente não apenas da integração entre atividades manufatureiras e de pesquisa e desenvolvimento, mas sobretudo em função da maior interdisciplinaridade que vem ocorrendo no desenvolvimento de novas tecnologias. Desse modo, a busca por sinergias entre diferentes projetos é um objetivo importante para redução de custos via economias de escopo.

O presente trabalho se inspira em Andreoni (2017) para construir uma matriz que relacione tecnologias e setores demandantes - chamada a partir daqui, simplificadamente, de Matriz Tecnológica. Essa matriz relaciona, em uma dimensão, as chamadas Bases de Conhecimento ou Tecnologias Habilitadoras (Key Technologies), ou seja, tecnologias com fundamentações e necessidades similares de desenvolvimento. A outra dimensão da análise diz respeito aos setores que seriam os seus principais demandantes.

Essa visão matricial permite que seja vista de modo simples e simultâneo quais são as bases de conhecimento mais transversais e quais são setores mais "diversificados" do ponto de vista tecnológico. Acredita-se que o mapeamento originado da Matriz Tecnológica permite a busca por Bases de Conhecimento mais transversais e que afetam múltiplos segmentos, bem como as sinergias entre os diversos setores. Sendo assim, pode-se identificar onde seria possível priorizar simultaneamente o desenvolvimento tecnológico (a política de inovação) e o desenvolvimento da competividade dos setores (a política industrial).

\subsection{Referencial Analítico}

A inovação pode ser caracterizada como um processo complexo de experimentação e que ocorre, em geral, em contextos dinâmicos e sob grande incerteza. Neste processo de tentativa e erro, a continuidade, o aprendizado e o acúmulo de competências são aspectos centrais. Hoje ela é resultado muito mais de processos contínuos e estruturados realizados dentro das empresas - nos mais diversos setores - do que de lampejos individuais. A estrutura produtiva, as condições de produção de conhecimento (recursos físicos, humanos e financeiros) e os desafios colocados a cada tempo, podem ser entendidos como fatores determinantes da evolução tecnológica. Além disso, há um aumento no transbordamento intrassetorial e intersetorial nos novos desenvolvimentos tecnológicos. Um exemplo disso são as tecnologias militares, que historicamente são vistas como drivers tecnológicos, mas que cada vez mais fazem o caminho inverso, ou seja, valem-se do maior dinamismo das evoluções no mercado civil para depois encontrar aplicações militares. (Squeff, 2016)

Nesse sentido, mapear quais são as tecnologias emergentes e quais são as atividades econômicas, novas ou tradicionais, buscando-se valer delas para introduzir novos produtos ou novas formas de produzir se converteu em uma das principais ferramentas das políticas industriais modernas (ANDREONI, 2017). Como mencionado na seção anterior, alguns países estão desenhando novas políticas a partir desse referencial. 
Como um primeiro esforço para desenvolver um mapeamento para o Brasil, o presente trabalho adotou como referência o instrumento proposto por Andreoni (2017) para construção do que aqui chamamos de Matriz Tecnológica. Neste trabalho o autor relaciona o que ele denominou como "plataformas tecnológicas" ou "tecnologias chave"12 com os diferentes tipos de cadeias de suprimentos $^{13}$. Assim, é possível ver as interações e transbordamentos entre estas duas dimensões, buscando-se economias de escopo, união de esforços e redução de custos no desenvolvimento tecnológico.

\section{Figura 1: Exemplo Estilizado da Matriz Tecnológica}

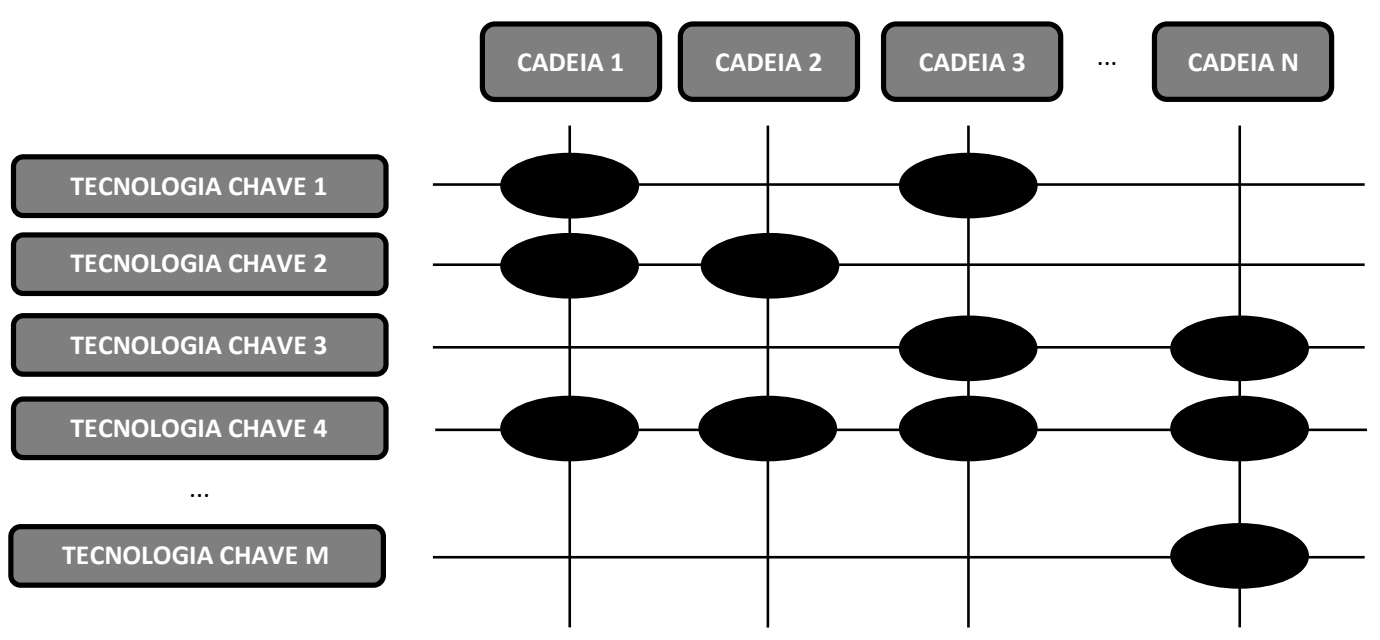

Fonte: Elaboração própria, baseado em Andreoni (2017)

\subsection{Aplicação da Metodologia}

Visando à aplicação da metodologia e obtenção de insumos para a construção da Matriz Tecnológica, foi realizada uma consulta junto a algumas equipes do Banco Nacional de Desenvolvimento Econômico e Social (BNDES). A estrutura organizacional do BNDES para o tratamento junto às empresas e projetos de investimento prima pela especialização setorial, ou seja, há departamentos específicos, por exemplo, para o setor de bens de capital, para a indústria química, para o complexo da saúde, para a mineração e siderurgia, entre outros. Dentro desses departamentos setoriais há equipes dedicadas à absorção e geração de conhecimentos sobre esses respectivos setores. Essas equipes são responsáveis por acompanhar a conjuntura e a tendência dos setores, além de, frequentemente, fazer o papel de interlocução entre o BNDES, os demais agentes do setor público, as empresas e as associações empresariais. Além disso, elas são frequentemente convidadas a participar ativamente na formulação de políticas públicas para o desenvolvimento dos setores que acompanham. O conjunto de equipes técnicas de acompanhamento setorial formou o grupo de trabalho que deu suporte à aplicação da metodologia.

A metodologia foi implementada por meio de dois formulários, aplicados em momentos distintos. O primeiro formulário, aplicado entre junho e setembro de 2017 , buscava identificar os principais desafios de longo prazo que devem ser enfrentados pelos setores e quais são as tecnologias que estão sendo desenvolvidas para superá-los. O segundo formulário buscava identificar o ambiente institucional em que os setores estão envoltos para entender os principais entraves que impedem o desenvolvimento e aplicação de novas tecnologias por eles e foi aplicado

\footnotetext{
${ }^{12}$ Sistemas de pesquisa e desenvolvimento ou tecnologias que apresentem algumas características similares necessárias ao seu desenvolvimento perpassam a economia por mais de uma cadeia de valor ou setor.

${ }^{13}$ As cadeias propostas são: i) bens de consumo final; ii) componentes; iii) tecnologias para produção; iv) tecnologias de serviços; v) matérias-primas.
} 
entre setembro e novembro de 2017. Ambos os formulários contaram com o mesmo número de respondentes, que totalizaram 16 (dezesseis) respondentes.

É importante destacar que a metodologia não foi aplicada pensando-se em todos os setores da economia. Neste momento ele ficou restrito apenas às atividades agrícolas (essencialmente as partes industriais e de processamento), de mineração e de indústria. Não há prejuízos ou inconsistência na aplicação da metodologia para outras áreas, como serviços e infraestrutura. A restrição se deu apenas por uma questão de limitação do número de respondentes consultados e trabalhos futuros poderão explorar esse espaço.

\section{A MATRIZ TECNOLÓGICA}

Ainda que baseado no modelo descrito na seção anterior, algumas distinções metodológicas para construção da matriz foram inseridas. As duas dimensões propostas originalmente foram levemente modificadas, ainda que mantendo o espírito do arcabouço original. Primeiramente, ao invés de partir das Tecnologias Habilitadoras, partiu-se diretamente das tecnologias. Assim, o elemento mais básico de análise não foram grandes grupos definidos previamente de modo discricionário. Optou-se por adotar um modelo em que, a partir da lista de tecnologias encaminhada, foram construídas as agregações que compõem as linhas da Matriz Tecnológica. Sendo assim, não houve obrigatoriedade de que cada respondente analisasse de modo exaustivo como cada Tecnologia Habilitadora pode impactar seu setor.

Já no caso das colunas da Matriz Tecnológica, não foi adotado o recorte de "cadeias de valor" sugerido por Andreoni (2017), mas sim a divisão clássica da indústria em seus segmentos "consagrados". Entendeu-se que criar outra taxonomia que não aquela já usualmente trabalhada pelos respondentes seria um complicador desnecessário para a exploração aqui iniciada. No entanto, é importante ressaltar que, caso seja necessário, essa classificação pode ser reescrita a partir dos segmentos desenhados. ${ }^{14}$

O primeiro formulário, como mencionado, buscou identificar os desafios enfrentados pelos setores e as tecnologias que estão sendo desenvolvidos para tentar solucioná-los. O formulário enviado contava com os campos descritos na Tabela 1 abaixo.

Tabela 1: Campos do Formulário da Matriz Tecnológica

\begin{tabular}{|l|l|}
\hline Tecnologia & \multicolumn{1}{|c|}{ Descrição do Campo } \\
\hline Desafio & $\begin{array}{l}\text { Inovação, de produto ou de processo, não necessariamente } \\
\text { disruptiva, que está sendo desenvolvida; }\end{array}$ \\
\hline Setor & $\begin{array}{l}\text { Qual é o desafio que a tecnologia busca enfrentar (ex: } \\
\text { aumento da produtividade, reduzir o impacto ambiental, } \\
\text { segurança nacional, etc); }\end{array}$ \\
\hline $\begin{array}{l}\text { Prazo esperado de } \\
\text { implantação }\end{array}$ & $\begin{array}{l}\text { Em qual setor a referida tecnologia será aplicada; } \\
\text { quando a tecnologia estará difundida em parcela relevante } \\
\text { do mercado, a ponto de os impactos esperados já serem } \\
\text { percebidos. Foram adotados como referência os seguintes } \\
\text { prazos: i) Curto (até 2022); ii) Médio (até 2030); iii) } \\
\text { Longo (após 2030) }\end{array}$ \\
\hline
\end{tabular}

\footnotetext{
${ }^{14}$ Pode-se dar uma ótica, por exemplo, a partir de etapas produtivas (reescrevendo "Celulose" e "Siderurgia", como "Bens Intermediários"), ou de complexos produtivos ("Celulose", "Química" e "Fármacos", como "Complexo Químico"), ou qualquer outra agregação que seja necessária.
} 


\begin{tabular}{|l|l|}
\hline Campo & \multicolumn{1}{|c|}{ Descrição do Campo } \\
\hline \multirow{3}{*}{ Impacto esperado } & $\begin{array}{l}\text { Foram adotados três referenciais de impacto: i) Moderado, } \\
\text { quando a tecnologia é importante, mas muda apenas } \\
\text { marginalmente a organização e/ou a forma de produzir no } \\
\text { setor; ii) Elevado, quando a tecnologia traz grandes } \\
\text { mudanças/avanços na organização e/ou a forma de } \\
\text { produzir no setor; e iii) Disruptivo, quando a tecnologia é } \\
\text { capaz de mudar paradigmas no setor, introduzindo novas } \\
\text { categorias de produtos e formas de produzir bem } \\
\text { diferentes das vigentes; }\end{array}$ \\
\hline
\end{tabular}

Fonte: Elaboração Própria

Os três campos iniciais eram de preenchimento livre, ou seja, continham apenas as instruções da descrição e os participantes eram livres para responder segundo a melhor conveniência. Apenas os dois últimos campos continham opções de respostas, cabendo aos respondentes apenas selecionar aquela que melhor se encaixava nas suas perspectivas.

Como era de se esperar, o grau de detalhamento das informações foi bastante heterogêneo, tanto entre os respondentes e, por vezes, dentro das informações dos próprios respondentes. A intensidade tecnológica dos setores e o grau de maturidade de cada tecnologia podem ser apontados como as principais razões para essa heterogeneidade. Adicione-se a isso que, como uma parte do conhecimento aplicado era tácita, há uma dificuldade natural em enquadrá-la dentro de um conceito pré-estabelecido por outrem. Para superar esse desafio reuniões individuais e coletivas foram realizadas entre os autores e os respondentes envolvidos, assim, os conceitos e o nível de detalhe foram amadurecidos de modo conjunto.

O resultado final desta etapa foi a construção de uma espécie de "banco de tecnologias e aplicações", que se constituem no nível mais desagregado de análise, ou seja, podemos considerá-lo como o conjunto de "microdados" que compõe a Matriz Tecnológica. Esse banco possui cerca de 350 tecnologias em desenvolvimento ou sendo aplicadas para uso em pouco mais de 15 segmentos produtivos. Um conjunto de informações dessa natureza é certamente bastante rico, no entanto, leva a dificuldades analíticas pelo seu tamanho. Assim, coube aos autores do presente trabalho agregar as informações e colocá-las em um novo nível, mais sintético e com base em uma taxonomia própria $^{15}$.

A taxonomia adotada no estudo foi denominada "Bases de Conhecimento". Essas Bases buscam unir tecnologias ou aplicações que partem de um conjunto de necessidades similares. As Bases foram nomeadas a partir de conceitos que são de uso corriqueiro quando se fala em grupos de tecnologia, como, por exemplo, "Biotecnologia" ou então nomenclaturas que expressassem bem o conjunto de tecnologias contidas numa mesma base, como, por exemplo, "Materiais Avançados". Ainda que bastante similar à ideia de plataformas tecnológicas propostas em Andreoni (2017), as Bases de Conhecimento tentam ser um pouco mais abrangentes ao tentar incorporar também melhorias em tecnologias difundidas e engenharia aplicada, não se restringindo apenas às tecnologias de ponta.

Dois níveis de agregação foram construídos para compilar as informações das tecnologias e suas aplicações (os "microdados"): i) nível de divulgação, chamado de "Bases de Conhecimento Nível 1", para ser usado na divulgação pública da Matriz Tecnológica, como é o caso do presente trabalho; ii) nível de trabalho, chamado de "Bases de Conhecimento - Nível 2", para ser usado

\footnotetext{
${ }^{15}$ Buscou-se alguma forma de classificação padronizada em que fosse possível enquadrar as tecnologias, no entanto, os resultados desse esforço mostraram-se não satisfatórios. Uma classificação utilizada por vezes no estudo de tecnologias e patentes é a International Patent Classification (IPC), mas essa classificação tem como objetivo principal o registro de propriedade intelectual, não o estudo em si de tecnologias e políticas para seu desenvolvimento.
} 
eventualmente, contando com maior nível de detalhe e que pode ser usado para desenhos específicos de políticas e instrumentos. A Tabela 2 apresenta esses dois níveis.

Tabela 2: Bases de Conhecimento da Matriz Tecnológica

\begin{tabular}{|c|c|}
\hline \multicolumn{2}{|c|}{ BASES DE CONHECIMENTO } \\
\hline Nível de Divulgação & Nível de Trabalho \\
\hline \multirow{3}{*}{ Advanced Analytics } & Algoritmos e Programação \\
\hline & Inteligência Artificial e Big Data \\
\hline & Modelagem e Simulação \\
\hline \multirow{4}{*}{ Biotecnologia } & Bioinsumos e Biomateriais \\
\hline & Bioprocessos \\
\hline & Células-tronco \\
\hline & Genética e Genômica \\
\hline \multirow{3}{*}{ Eletrônica e Ótica Avançadas } & Eletrônica Avançada \\
\hline & Ótica e Optoeletrônica \\
\hline & Sensores \\
\hline \multirow{5}{*}{ Manufatura Padrão e Avançada } & Manufatura Híbrida/Aditiva \\
\hline & Equipamentos e Dispositivos, exceto Robótica \\
\hline & Engenharia de Processo \\
\hline & Robótica \\
\hline & Sistemas de Controle e Monitoramento \\
\hline \multirow{4}{*}{ Materiais Avançados } & Grafeno \\
\hline & Materiais Compósitos \\
\hline & Novas Ligas Metálicas \\
\hline & Outros Materiais \\
\hline Nanotecnologia & Nanotecnologia \\
\hline \multirow{2}{*}{ Processos Físico-Químicos } & Processos Mecânicos \\
\hline & Processos Químicos \\
\hline \multirow{2}{*}{ Redes de Comunicação } & Softwares para Redes de Comunicação \\
\hline & Hardwares para Redes de Comunicação \\
\hline \multirow{3}{*}{ Sistemas de Energia } & Armazenamento de Energia \\
\hline & Geração e Recuperação de Energia \\
\hline & Smart Grid \\
\hline
\end{tabular}

Fonte: Elaboração Própria

A última etapa da metodologia de construção da Matriz Tecnológica foi definir como as informações entre tecnologias e setores seriam relacionadas entre si para formar a parte interna da Matriz. Os desafios aqui foram como atribuir graus de importância para cada tecnologia e também como lidar com eventuais heterogeneidades das informações ainda restantes, como tecnologias mais bem descritas (ou seja, desagregadas, ocupando mais de uma linha no banco de tecnologias) e setores "naturalmente" mais intensivos em inovações tecnológicas. Reconhecer esses desafios foi importante para evitar vieses em ambos os sentidos, ora para as Bases de Conhecimento, ora para os setores. 
Foi criado então um algoritmo simples, mas multicritério, que ponderou as tecnologias por meio de pontos, segundo a intensidade tecnológica de cada setor (número de tecnologias apontadas para aquele setor). Foram utilizados dois critérios em cada tecnologia. O primeiro foi o prazo esperado para a sua implantação: i) Curto, três pontos; ii) Médio, dois pontos; iii) Longo, um ponto. O segundo critério foi o impacto esperado: i) Moderado, um ponto; ii) Elevado, três pontos; iii) Disruptivo, cinco pontos. Assim, as tecnologias mais valorizadas são aquelas de impacto disruptivo e prazo de implantação já curto (oito pontos), enquanto as tecnologias menos valorizadas são aquelas de impacto moderado e prazo de implantação longo (dois pontos). Além disso, pode-se observar que se atribuiu um peso maior ao impacto esperado da tecnologia, ou seja, entendeu-se que tecnologias cuja expectativa seja gerar grandes impactos devem ter mais atenção na formação da Matriz (e de políticas derivadas) relativamente àquelas tecnologias que simplesmente já estejam a ponto de serem implementadas.

A última etapa foi somar os pontos das tecnologias para cada Base de Conhecimento em cada setor. Essa soma foi então relativizada em cada segmento, de modo que as colunas da matriz passassem a somar $100 \%$. As Bases de Conhecimento que mais se destacaram dentro de cada segmento foram então marcadas gradativamente na Matriz Tecnológica. Desse modo podemos observar quais são as Bases de Conhecimento mais relevantes para cada setor analisado e o conjunto de bases de conhecimento que são mais transversais entre estes setores. A Figura 2 mostra o resultado final da metodologia, a Matriz Tecnológica. 
Figura 2: Matriz Tecnológica

\begin{tabular}{|c|c|c|c|c|c|c|c|c|c|c|c|c|c|c|c|c|c|}
\hline \multirow[b]{2}{*}{$\begin{array}{c}\text { BASES DE } \\
\text { CONHECIMENTO }\end{array}$} & \multicolumn{16}{|c|}{ SETORES } & \multirow[b]{2}{*}{ 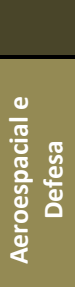 } \\
\hline & 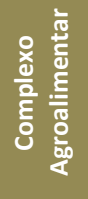 & $\begin{array}{l}\overline{\mathbb{J}} \\
\text { पू } \\
\text { 흔 }\end{array}$ & 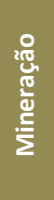 & $\begin{array}{l}\text { ๖ } \\
\text { ¿ }\end{array}$ & 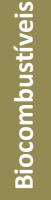 & 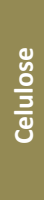 & $\frac{\bar{g}}{\frac{0}{\circ}}$ & 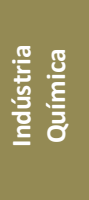 & 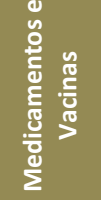 & 造 & 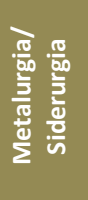 & 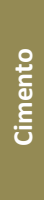 & 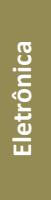 & 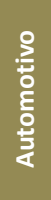 & 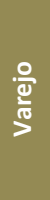 & 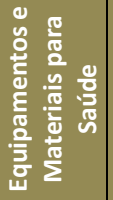 & \\
\hline \multicolumn{18}{|l|}{ Advanced Analytics } \\
\hline \multicolumn{18}{|l|}{ Biotecnologia } \\
\hline \multicolumn{18}{|c|}{ Eletrônica e Ótica Avançadas } \\
\hline \multicolumn{18}{|l|}{$\begin{array}{l}\text { Manufatura Padrão e } \\
\text { Avançada }\end{array}$} \\
\hline \multicolumn{18}{|l|}{ Materiais Avançados } \\
\hline \multicolumn{18}{|l|}{ Nanotecnologia } \\
\hline \multicolumn{18}{|l|}{ Processos Físico-Químicos } \\
\hline \multicolumn{18}{|l|}{ Redes de Comunicação } \\
\hline Sistemas de Energia & & & & & & & & & & & & & & & & & \\
\hline
\end{tabular}

Legenda:

Base de Conhecimento não identificada para o setor

Base de Conhecimento relevante para o setor

Base de Conhecimento bastante relevante para o setor

Base de Conhecimento extremamente relevante para o setor

Fonte: Elaboração Própria 
Após a construção da Matriz Tecnológica, é possível destacar alguns resultados sobre os desafios apontados e as bases de conhecimento mais destacadas, que na verdade ilustram o potencial analítico da ferramenta. A matriz permite uma leitura através das linhas mostrando como as tecnologias se difundem pelos diversos setores. Pelas colunas é possível observar quais setores tem maior capacidade de absorção de bases de conhecimento. Desta maneira, primeiramente, chama a atenção o maior destaque para tecnologias e aplicações nas Bases de Conhecimento "Manufatura Padrão e Avançada" e "Eletrônica e Ótica Avançadas". Além de aparecer com mais intensidade na Matriz Tecnológica, a primeira é também a única Base de Conhecimento comum a todos os segmentos. Na Tabela 2, podemos ver que essa base reúne tecnologias que lidam com o chamado "chão de fábrica", ou seja, tecnologias sobre as formas de produzir. Não por menos, um dos principais desafios que foi apontado nos formulários foi o aumento da produtividade, que visa conferir maior competitividade à indústria no curto e no médio prazo. Além disso, levando-se em conta que o presente estudo está focado em atividades cujo resultado final são produtos físicos, ou seja, produção de commodities e bens industriais, é um resultado que não causa muito espanto. Apesar dessa grande transversalidade, por vezes esses investimentos estavam associados a desafios específicos, como scale up de algumas biotecnologias ou o desenvolvimento do novo paradigma da fábrica submarina no caso de petróleo. No entanto, vale ressaltar que a sua intensidade revela que a atividade produtiva da indústria ainda é bastante importante, independentemente do crescimento do setor de serviços e da maior integração entre estas atividades. Uma evidência disso é o retorno do uso de políticas industriais mesmo nos países centrais.

Uma segunda Base de Conhecimento que chama a atenção é "Biotecnologia". Ela possui simultaneamente um grau elevado de transversalidade, ou seja, foi indicada por vários setores, como também possui um grau elevado de intensidade, apresentando várias tecnologias importantes para esses setores. Nesse caso, as tecnologias associadas tentam enfrentar dois desafios. O primeiro deles é a redução do impacto ambiental das atividades produtivas, por exemplo, por meio de novos processos com menor impacto ambiental. Outro motivo para a importância desta Base de Conhecimento é o desenvolvimento do potencial da chamada "economia verde", ou seja, muitas das tecnologias apontadas estão vinculadas à utilização de recursos renováveis, manuseados de modo sustentável, para desenvolver novos produtos, materiais e processos. Por vezes os dois desafios estão, inclusive, associados, como bioprocessos e biomateriais substituindo fatores de produção antigos e mais poluentes. Essa Base de Conhecimento é particularmente interessante por que o Brasil costuma ser apontado exatamente como um potencial polo de economia verde, com os setores produtivos se valendo da nossa diversidade de recursos naturais na geração de renda. Ao aparecer com destaque na Matriz Tecnológica, isso significa que não só nossos recursos naturais são hoje importantes elos produtivos, mas há também toda uma gama de possibilidades tecnológicas futuras que devem ser desenvolvidas, abrindo oportunidades para o adensamento das cadeias produtivas relacionadas.

Já olhando pelo lado dos setores é preciso destacar o grande potencial tecnológico ainda existente no setor de "Petróleo e Gás", com potencial de desenvolvimento em quase todas as Bases de Conhecimento. A atividade de exploração offshore, em conjunto com a visão estruturante da "fábrica de exploração submarina", desenham um grande eixo demandante de novas tecnologias, especialmente de equipamentos e materiais avançados. Os dois setores ligados à saúde ("Medicamentos e Vacinas" e "Equipamentos e Materiais para Saúde") também aparecem como grandes drivers, especialmente pelo desafio no desenvolvimento de medicamentos mais precisos (os chamados "nanomedicamentos") e novos aparelhos eletromédicos. Um último segmento que merece destaque é o de "Aeroespacial e Defesa", tradicionalmente um grande desenvolvedor de tecnologias ele tem apontamentos em praticamente todas as Bases de Conhecimento, com destaque para as tecnologias de "Advanced Analytics" ligadas à defesa cibernética e ao uso de inteligência artificial e big data para a identificação de ameaças.

Mas não apenas as transversalidades são análises importantes na matriz, há individualidades que também devem ser destacadas. Como comentários individuais não podem deixar de ser 
mencionados, em primeiro lugar, a intensidade de tecnologias da Base de Conhecimento "Sistemas de Energia" para o setor "Automotivo". Isso se deve ao desenvolvimento e o avançado de tecnologias ligadas ao carro elétrico, especialmente nos conjuntos de powertrain elétrico e de baterias. Outro destaque é o grande uso de inteligência artificial e big data no setor de "Varejo", para mapear as tendências de consumo, antever os desejos dos consumidores e fornecer tecnologias com maior agilidade e segurança aos meios de pagamento.

Assim, a metodologia adotada na Matriz Tecnológica permite tanto uma visão agregada das principais bases de conhecimento necessárias para o desenvolvimento dos distintos setores da economia, como também permite observar aspectos relativos a uma tecnologia específica que podem representar oportunidades relevantes para o desenvolvimento de um determinado setor da economia. Combina-se, assim, um olhar abrangente (ou "macro") sobre a dinâmica tecnológica na indústria a um olhar específico que atinge o nível de projeto de desenvolvimento e de cada setor individualmente.

Após a elaboração da Matriz Tecnológica, o passo seguinte foi identificar alguns elementos estruturais que definem as condições que atualmente moldam o potencial de desenvolvimento e absorção tecnológico no Brasil. Uma breve descrição do "Ambiente Institucional" é o alvo da próxima seção.

\section{AMBIENTE INSTITUCIONAL}

Nenhuma política pública deve ser desenhada sem que se leve em conta o ambiente no qual ela está inserida. Quando falamos de uma política tecnológica é importante entender como estão colocados os condicionantes tanto de desenvolvimento como de chegada da tecnologia ao mercado. Enquanto a seção anterior buscou evidenciar as oportunidades tecnológicas que os setores estão construindo para superar seus desafios, nesta etapa será feita uma análise de quais são os condicionantes necessários e os entraves existentes para que estas rotas possam ser desenvolvidas e/ou absorvidas no Brasil. A essa análise deu-se o nome de "Ambiente Institucional".

Foram definidas quatro camadas de análise: 1) a estrutura industrial; 2) a infraestrutura de ciência, tecnologia e inovação $(\mathrm{C}, \mathrm{T} \& \mathrm{I})$; 3 ) o arcabouço regulatório; e 4) os instrumentos de fomento e financiamento. Estas dimensões condicionam e definem eventuais restrições e oportunidades para o desenvolvimento tecnológico bem como podem reconfigurar segmentos e cadeias criando oportunidades para os setores. Sendo assim, a junção dessas duas óticas, da Matriz Tecnológica e do Ambiente Institucional, permite a construção de uma agenda tecnológica que é simultaneamente de política de inovação e de política industrial.

Para esta etapa foi passado um segundo formulário aos respondentes. No entanto, desta vez o objetivo foi extrair mais do que respostas objetivas, a ideia é que fosse encaminhado um pequeno diagnóstico contemplando as quatro camadas supracitadas. Para tanto dever-se-ia ter em mente as principais tecnologias apontadas na fase anterior e os setores que foram elencados. Do ponto de vista conceitual foi definido o que se pretendia em cada uma das quatro camadas.

Sobre a estrutura industrial existente o objetivo era entender se ela seria capaz de produzir e/ou absorver essas tecnologias no País, assim foi pedido que: a) fossem identificadas quais são as principais empresas; b) qual o perfil dessas empresas, se elas são de grande ou menor porte, se possuem capacidade de engenharia interna e equipe de $\mathrm{P}, \mathrm{D} \& \mathrm{I}$ própria ou atuam predominantemente em parceria com outras instituições e qual a origem de capital dessas empresas (nacional, multinacional estrangeira); c) identificar quando possível se as empresas já realizam pesquisas relevantes relacionadas aos desafios listados e às bases de conhecimento identificadas.

O tópico seguinte a ser abordado foi a infraestrutura de Ciência, Tecnologia e Inovação (C,T\&I). Buscou-se averiguar: a) quais as principais instituições de ciência e tecnologia (ICTs) com atividades de P,D\&I para os setores e como é a participação nos projetos de desenvolvimento; b) a adequação da infraestrutura das ICTs existentes e se ela é suficiente para atingir os objetivos 
esperados e viabilizar os projetos/desafios identificados; e c) se há projetos em andamento de ampliação dessa infraestrutura no momento.

Já as perguntas sobre o ambiente regulatório buscavam entender se: a) a presença de um arcabouço regulatório é relevante para a atividade do setor; b) quais os principais vetores e motivos relevantes que definem o contexto regulatório (ex.: redução de emissões, mudança climática, segurança do trabalho, necessidade de concessão de permissão para exploração/ atuação/produção, etc; c) se o arranjo institucional é bem definido; d) quais as principais instituições relacionadas ao arcabouço regulatório do setor; e) se há iniciativas relevantes de revisão e/ou elaboração de marco regulatório em andamento; e f) qual a relevância do arcabouço regulatório para o desenvolvimento de novas tecnologias.

Por fim, a última camada tratava sobre os instrumentos e mecanismos de fomento (financiamento e outros). Entendeu-se que era importante averiguar: a) se as linhas (e estrutura) de crédito existentes são adequadas e suficientes; b) quais as principais instituições de fomento que atendem o setor (BNDES, Agências Estaduais de Desenvolvimento, Bancos regionais, outros); c) se há fonte setorial específica de recursos não-reembolsáveis e se essas fontes atendem às necessidades ou precisariam ser modificadas; d) se existem incentivos tributários e fiscais relevantes para o setor; e e) se há alguma política garantidora ou direcionadora de demanda para a base produtiva local, como compras públicas ou requisitos de conteúdo de local ${ }^{16}$.

Como mencionado, cada respondente elaborou um pequeno diagnóstico dos setores sob a sua responsabilidade. Fugiria do escopo do presente trabalho apresentar em detalhes cada relatório elaborado, assim, o que há seguir é um compilado com os aspectos gerais manifestados pelos respondentes. Não se trata, necessariamente, de um consenso entre esses aspectos ou mesmo de um ranking de elementos que mais apareceram. A ideia principal é apenas ilustrar parte do potencial do trabalho aqui referido e evidenciar os desafios mais horizontais ou que encontrem respaldo em segmentos similares, permitindo assim uma visão mais ampla do ambiente institucional e dos desafios que cercam o desenvolvimento tecnológico e o futuro da indústria.

Sobre a Estrutura Industrial, o principal desafio apontado foi a base industrial brasileira ser em grande parte multinacional, com essas empresas sendo as líderes da maior parte dos mercados, com a maior exceção sendo o Varejo, onde as líderes são majoritariamente grandes empresas de capital nacional. Uma base de líderes multinacionais representa um desafio a qualquer política industrial e tecnológica uma vez que os processos decisórios que determinam os investimentos em inovação ficam centrados nos países sedes e não no Brasil. Restringe-se, assim, a autonomia para a tomada de decisão local e a governança e o alcance dos incentivos sobre o processo de P,D\&I. Somando-se a isso que as empresas brasileiras acabam tendo um porte relativamente menor - muitas vezes até absolutamente - o investimento em P\&D é sistematicamente baixo, tornando essas empresas seguidoras e/ou com foco em tropicalização de tecnologias.

É importante mencionar que não foi apontado que exista um problema intrínseco que impeça uma maior integração entre empresas e universidades ${ }^{17}$. Assim, o quadro de baixa integração entre esses dois agentes parece decorrer de problemas estruturais ligados à falta de projetos mais sofisticados e da falta de capacidade de concertação dos atores públicos e privados em torno de uma estratégia de desenvolvimento de longo prazo, fatores esses que levariam ao baixo nível sistêmico de P,D\&I que há no país.

$\mathrm{Na}$ mesma linha, quando analisamos a terceira camada do Ambiente Institucional, a infraestrutura de C,T\&I observa-se que, ainda que haja grande heterogeneidade entre as estruturas e

\footnotetext{
${ }^{16}$ As políticas de demanda devem ser compreendidas no seu sentido mais abrangente, isto é, desde mecanismos de demanda direta do setor público (a exemplo das PDPs de saúde, ou parcerias público-privadas como os leilões de energia), a outros mecanismos que atuam na conformação e direcionamento da demanda (a exemplo das políticas de conteúdo local ou mesmo políticas que incentivem a inserção no mercado de novas soluções, a exemplo de isenções tributárias para tecnologias inovadoras).

17 Por sinal, foram apontados pontos positivos favoráveis à integração, como alguns instrumentos que financiam essas parcerias, por exemplo, o Fundo de Tecnologia do BNDES, que apoia projetos de inovação com recursos não-reembolsáveis, bem alguns instrumentos da Finep e das fundações de amparo à pesquisa.
} 
necessidades de cada segmento, na média, ela foi considerada adequada às necessidades da indústria. No entanto, deve-se pesar que isso talvez seja um reflexo do baixo grau de exigência dos projetos desenvolvidos. ${ }^{18}$ Por fim, o atual cenário de falta de recursos para ciência e tecnologia está impedindo alguns investimentos pontuais de adequação ou modernização da infraestrutura que no médio/longo prazo podem se tornar uma restrição mais generalizada, revertendo o atual diagnóstico.

O ambiente regulatório, quarta camada analisada, é específico em cada setor. Por exemplo, alguns setores não apresentam nenhum tipo de regulação específica para suas atividades, alguns apresentam algumas poucas normas a serem seguidas (como emissão de poluentes no setor automotivo) e outros são mais regulados (como é o caso do complexo da saúde e dos alimentos). Não foi apontado nenhum problema estrutural de relacionamento com as agências reguladoras que impeça que inovações ocorram ou sejam implementadas ${ }^{19}$. No entanto, um desafio que parece estar presente para os setores que necessitam de registro de patentes em função dos longos processos de avaliação e registro no Instituto Nacional de Propriedade Intelectual (INPI).

A última camada analisada foram os instrumentos de fomento e financiamento para P,D\&I. Historicamente há instrumentos reembolsáveis e não-reembolsáveis disponíveis no Brasil. No entanto, recentemente os primeiros ficaram relativamente mais caros, enquanto o segundo grupo está mais escasso. Apenas a título de exemplo, o aumento da "restrição fiscal" tem reduzido o espaço no orçamento para recursos não-reembolsáveis e/ou subsidiados. Além disso, mesmo os setores que contam com fundos setoriais específicos enfrentam frequentes problemas de contingenciamento, dificultando assim tanto ações mais estruturais como pequenos projetos. Alguns instrumentos mais horizontais de políticas públicas foram apontados como importantes, como a Lei do Bem e a criação da Empresa Brasileira de Pesquisa e Inovação Industrial (Embrapii).

Além disso, dos instrumentos disponíveis, apenas em alguns setores há a possibilidade de se usar encomendas públicas ou de se beneficiar de demanda regulada - para a maioria dos setores os esforços inovativos são decorrentes do nível de atividade ${ }^{20}$. Por fim, é importante ressaltar que quase todos os respondentes apontam para instrumentos que existiam, mas que vêm sofrendo recentemente um intenso processo de desarticulação, reduzindo assim o espaço de atuação de políticas públicas.

\section{CONCLUSÕES}

No presente estudo pretendeu-se construir um arcabouço analítico que tenha como unidade de análise a indústria. No entanto, buscou-se identificar também algumas oportunidades tecnológicas que estão sendo desenvolvidas para fazer frente aos novos desafios. Com o a conjunção dessas duas dimensões, pôde-se construir uma visão de futuro da indústria que sirva de insumo à eventuais proposições de políticas públicas. Partimos da premissa de que o setor industrial é importante não apenas por aquilo que produz, mas também pela estabilidade que permite ao Balanço de Pagamentos (que nem sempre é fornecido pelas exportações de commodities) e também pela sua grande cadeia produtiva (backward linkages), possuindo importantes efeitos multiplicadores, inclusive com uma integração cada vez maior com as atividades do setor de serviços.

Essa visão de futuro foi ancorada, primeiramente, na identificação de rotas tecnológicas e de setores demandantes mais promissores, representados na Matriz Tecnológica. Esse referencial analítico permitiu identificar simultaneamente as bases de conhecimento mais transversais "Manufatura Padrão e Avançada", "Eletrônica e Ótica Avançadas" e "Biotecnologia" - além de setores que são bastante diversificados nas suas demandas tecnológicas - "Petróleo e Gás", "Complexo da Saúde" e "Aeroespacial e Defesa".

\footnotetext{
${ }^{18}$ Também foi observado que há um grau de ociosidade elevada nos laboratórios de C,T\&I, sejam universidades ou outros institutos, o que implica em desafios para o custeio e manutenção dessas estruturas.

19 Ainda que eventualmente alguma nova tecnologia careça de regulação, esse é um problema pontual, pois a tecnologia surge antes da regulação.

${ }^{20}$ Vale também registrar que, atuando no fim do processo de inovação, as políticas garantidoras de demanda foram apontadas como relevantes para setores como saúde, petróleo e defesa, ainda que esta última tenha a maior inconstância dos três.
} 
Além dessa análise prospectiva, entendeu-se que era importante analisar o contexto em que a indústria brasileira está inserida. Assim, foi feita uma análise do ambiente institucional englobando alguns aspectos setoriais tais como a estrutura industrial, a infraestrutura de C,T\&I, o arcabouço regulatório e a existência e adequação de instrumentos financeiros e de fomento.

Podemos dizer que a Matriz Tecnológica é a parte propositiva, enquanto a análise do Ambiente Institucional é a parte restritiva, ou seja, enquanto a primeira permitiria dar uma "orientação de futuro" a respeito da indústria brasileira, a segunda tentaria entender quais são os aspectos que hoje limitam um maior desenvolvimento tecnológico. Apenas a junção desses tópicos permite um entendimento completo para a formulação de políticas públicas.

Diante do que foi exposto, é possível desenhar um conjunto de recomendações preliminares e que apenas ilustram um possível uso da Matriz - para tentar impulsionar o desenvolvimento tecnológico e a absorção, por parte da indústria nacional, de tecnologias de ponta. As ilustrações aqui mencionadas estão ligadas ao ambiente de inovação e são vistas como essenciais para que os projetos de inovação transcorram, inclusive de maneira cooperativa entre os diferentes agentes financiadores do desenvolvimento tecnológico.

\section{Tabela 3: Quadro de Sugestões}

Estruturação conjunta entre os setores público e privado de "missões", ou projetos orientados por missões, em especial no que tange aos três segmentos identificados como mais demandantes de tecnologias (Petróleo, Saúde e Aeroespacial e Defesa).

Destinar/reorientar uma parcela do orçamento (por exemplo, da Saúde e da Defesa) para as etapas finais de projetos de desenvolvimento tecnológico, notadamente de scale up e de compra dos produtos e serviços finais.

$\mathrm{O}$ aspecto anterior pode ser reforçado a partir da atuação das empresas estatais (por exemplo, do setor de Petróleo), orientadas para o investimento em tecnologias prioritárias.

Criar novos instrumentos financeiros (ou modernizar/racionalizar instrumentos existentes), por exemplo, estruturando um fundo integrado de inovação, para apoio às tecnologias identificadas na Matriz e/ou ofertando crédito em condições financeiras prioritárias para as máquinas e sistemas que incorporem componentes e serviços associados à Manufatura Avançada.

Estimular, inclusive por meio de agências de fomento, a participação de capital em empresas que estejam desenvolvendo, ou possam a vir desenvolver, tecnologias identificadas como pertencentes às Bases de Conhecimento prioritárias.

Promover a atuação conjunta das agências de fomento, explorando suas sinergias ao apoiar as instituições de ciência e tecnologia, notadamente em suas competências relacionadas às tecnologias habilitadoras e segmentos identificados pela Matriz.

Fonte: Elaboração Própria

Por certo, as sugestões aqui elencadas não são consideradas exaustivas para resolver os problemas ligados à competitividade da indústria. Especialmente no curto prazo, o baixo dinamismo recente da economia brasileira e a instabilidade de preços chave (juros e câmbio) são desafios persistentes. Como dito, as propostas sugestões apresentadas têm um caráter meramente ilustrativo e foram realizadas intencionalmente com um grau de generalidade mais elevado ${ }^{21}$. O intuito aqui foi o de ressaltar o potencial que a ferramenta da Matriz Tecnológica tem não apenas como um instrumento de diagnóstico, mas também para auxílio ao planejamento e formulação de políticas públicas.

\footnotetext{
${ }^{21}$ Entretanto, tal generalidade pode ser facilmente reduzida e ações e projetos podem ser detalhados de forma totalmente compatível com a construção oferecida no presente artigo.
} 


\section{REFERÊNCIAS}

ANDREONI, A. Industrial Ecosystems and Policy for Innovative Industrial Renewal: A New Framework and Emerging Trends in Europe. London: SOAS University of London, 2017. No prelo.

ANDREONI, A.; CHANG, H. J. Industrial Policy and the Future of Manufacturing. Economia e Politica Industriale: Journal of Industrial and Business Economics, Milano, v. 43, n. 4, p. 491-502, Spring 2016.

ANDREONI, A.; GREGORY, M. Why and how does Manufacturing still Matter: Old Rationales, New Realities. Revue d'Économie Industrielle, Valbonne, n. 144, p. 21-57, 4. tre. 2013.

BACHA, E.; DE BOLLE, M. (Org.). O Futuro da Indústria no Brasil: Desindustrialização em Debate. Rio de Janeiro: Ed. Civilização Brasileira, 2013.

BALDWIN, R. The Great Convergence: Information Technology and the New Globalization. Cambridge, MA: The Belknap Press of Harvard University Press, 2016.

BONELLI, R.; PESSOA, S.; MATOS, S. Desindustrialização no Brasil: Fatos e Interpretação. In BACHA, E.; DE BOLLE, M. (Org.) O Futuro da Indústria no Brasil: Desindustrialização em Debate. Rio de Janeiro: Ed. Civilização Brasileira, 2013. p. 45-80.

CHANG, H. J. Chutando a Escada: A Estratégia do Desenvolvimento em Perspectiva Histórica. São Paulo: Ed. Unesp, 2004.

CHANG, H. J.; ANDREONI, A.; KUAN, M. International Industrial Policy Experiences and the Lessons for the UK. London: UK Government Office of Science, 2013. (Policy Report for the UK Foresight Future of Manufacturing Project).

COHEN, S.; DELONG, B. Concrete Economics: The Hamilton Approach to Economic Growth and Policy. Boston: Harvard Business Review Press, 2016.

DAUDT, G.; WILLCOX, L. Reflexões Críticas a partir das Experiências dos Estados Unidos e da Alemanha em Manufatura Avançada. BNDES Setorial, Rio de Janeiro, n 44, p. 5-45, 2016.

HIRATUKA, C.; SARTI, F. Transformação na Estrutura Produtiva Global, Desindustrialização e Desenvolvimento Industrial no Brasil. Revista de Economia Política, São Paulo, v. 37, n. 1, p. 189-207, jan.-mar. 2017.

MAZZUCATO, M. The Entrepreneurial State. London: Anthem Press, 2013.

O'SUlliVAN, E.; ANDREONI, A.; LÓPEZ-GÓMEZ, C.; GREGORY, M. What is New in the New Industrial Policy? A Manufacturing Systems Perspective. Oxford Review of Economic Policy, Oxford, v. 29, n. 2, p. 432-462, Summer 2013.

PINHEIRO, M; FERREIRA, P.; PESSOA, S; SCHYMURA, L. Por que o Brasil não Precisa de Política Industrial. Rio de Janeiro: FGV, 2007. (Texto para Discussão, n. 644).

PREBISCH, R. O Desenvolvimento Econômico da América Latina e Alguns de seus Principais Problemas. 1949. In: BIELSCHOWSKY, R. (Org.). Cinquenta Anos de Pensamento na CEPAL. Rio de Janeiro: Ed. Record, 2000. v.1. p. 69-136.

RAUEN, A. (Org.) Políticas de Inovação pelo Lado da Demanda no Brasil. Brasília: IPEA, 2017.

ROSENBERG, N. Technological Change in the Machine Tool Industry, 1840-1910. The Journal of Economic History, Cambridge, UK, v. 23, n. 4, p. 414-443, Dec. 1963. 
SERRANO, F.; SUMMA, R. Macroeconomic Policy, Growth and Income Distribution in the Brazilian Economy in the 2000s. Investigación Económica, Ciudad de México, v. 71, n. 282, p. 55-92, oct.-dic. 2012.

SQUEFF, F. Sistema Setorial de Inovação em Defesa: Análise do Caso do Brasil. In DE NEGRI, F.; SQUEFF, F. (Org.). Sistemas Setoriais de Inovação e Infraestrutura de Pesquisa no Brasil. Brasília: IPEA, 2016. p. 63-113.

SQUEFF, G. Desindustrialização: Luzes e Sombras no Debate Brasileiro. Brasília: IPEA, 2012. (Texto para Discussão, n. 1747).

TASSEY, G. Modeling and Measuring the Economic Roles of Technology Infrastructure. Economics of Innovation and New Technology, v. 17, n. 7, p. 615-629, Oct-Nov. 2008.

THIRLWALL, A. A Plain Man's Guide to Kaldor's Growth Laws, Journal of Post Keynesian Economics, v. 5, n. 3, p. 345-358, 1983.

WADE, R. The Role of Industrial Policy in Developing Countries. In: CALCAGNO, A.; DULlIEN, S.; MÁRQUEZ-VELÁZQUEZ, A.; MAYSTRE, N.; PRIEWE, J. (Ed.) Rethinking Development Strategies after the Financial Crisis: Making the Case for Policy Space. New York: United Nations Publications, 2015. v.1.p. 67-79.

. The American Paradox: Ideology of Free Markets and the Hidden Practice of Directional Thrust. Cambridge Journal of Economics, Cambridge, UK, v. 41, n. 3, p. 859-880, May 2017. 